\title{
Using Electrochemical Impedance Spectroscopy Sinusoidal Potential Amplitude to Assess the Efficiency of Niobium Oxide Based Organic Coating in Oil Wells Produced Water
}

\author{
Rodrigo de Siqueira Melo ${ }^{1, *}$, Simone Louise Delarue Cezar Brasil ${ }^{2}$, Ladimir José de Carvalho ${ }^{2}$, \\ Leila Yone Reznik ${ }^{2}$ \\ ${ }^{1}$ Universidade Federal do Rio de Janeiro, UFRJ Campus-Macaé Professor Aloísio Teixeira, Av. \\ Aluizio da Silva Gomes, 50, Granja dos Cavaleiros, CEP: 27930-560, Macaé, RJ, Brazil. \\ ${ }^{2}$ Universidade Federal do Rio de Janeiro, Escola de Química, Departamento de Processos Inorgânicos, \\ Av. Athos da Silveira Ramos, 149, Bloco E, Sl E-206 - Ilha do Fundão, CEP: 21941-909, Rio de \\ Janeiro, RJ, Brazil. \\ *E-mail: rodrigosqm@macae.ufrj.br
}

doi: $10.20964 / 2016.12 .25$

Received: 18 August 2016 / Accepted: 29 September 2016 / Published: 10 November 2016

The oil industry coexists with damages caused by corrosion of materials in almost all areas of activity. Recent discoveries in Brazil of potential oil reserves at deeper waters, commonly named "pre-salt oil layer", may represent severe conditions leading to the need in developing new materials and technologies that meet unfavorable prospection demands. In this context, the corrosion protection characteristic of an organic coating based on niobium oxide immersed in water produced by oil wells was evaluated. The evaluation of the coating was carried out by means of electrochemical impedance spectroscopy technique (EIS). Results showed that only with the application of high voltage amplitudes of $350 \mathrm{mV}$ over the OCP it was possible to decrease dispersion in EIS data, with no degradation or delamination of the coating. Despite this, at high voltage sinusoidal signal and raising the agressivity of the medium, it was observed an increase in the corrosion mechanisms leading to lower impedance module values at longer exposure time (144 days), indicating the need for optimization of sinusoidal voltage amplitudes according with the nature, thickness and resistivity of the coating applied.

Keywords: electrochemical impedance spectroscopy, corrosion, organic coating, $\mathrm{Nb}_{2} \mathrm{O}_{5}$.

\section{$\underline{\text { FULL TEXT }}$}

(C) 2016 The Authors. Published by ESG (www.electrochemsci.org). This article is an open access article distributed under the terms and conditions of the Creative Commons Attribution license (http://creativecommons.org/licenses/by/4.0/). 